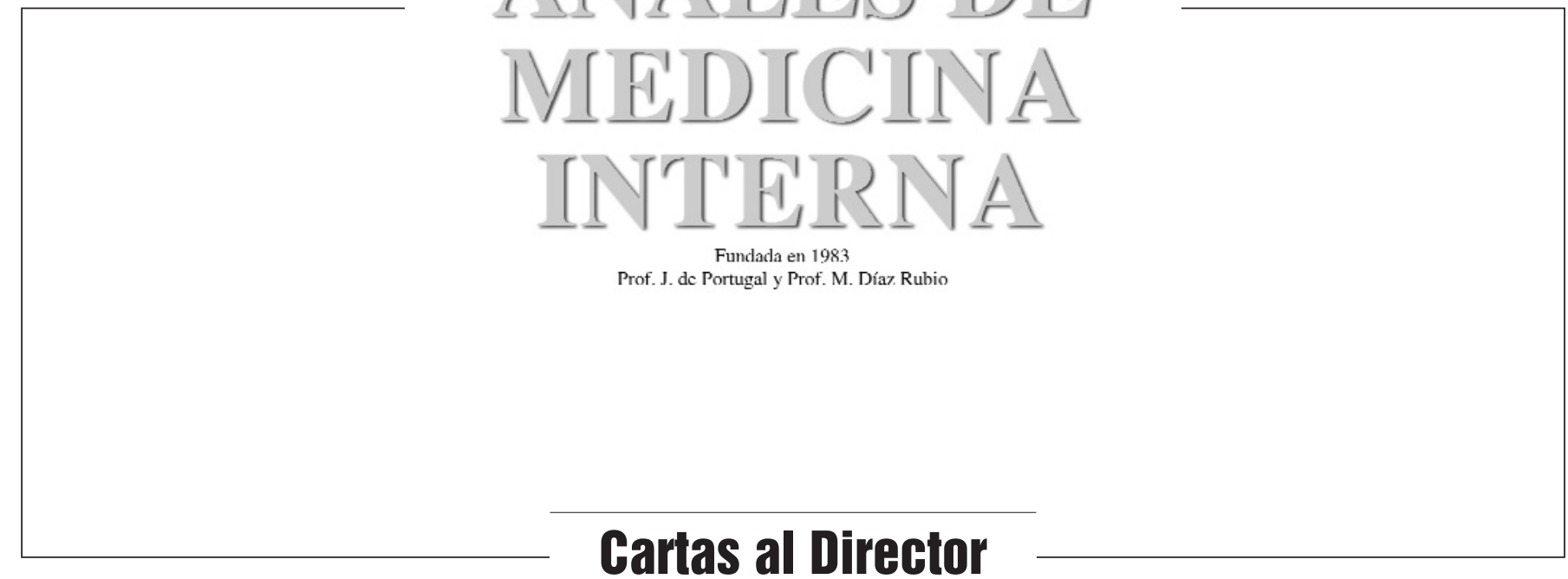

\section{Enteritis eosinofílica como causa de abdomen agudo}

\section{Sr. Director:}

La gastroenteritis eosinofílica es una entidad muy poco frecuente, con cerca de unos 50 casos descritos en España (1-3).Se caracteriza por infiltración de la mucosa digestiva por leucocitos eosinófilos maduros, fundamentalmente estómago e intestino delgado $(4,5)$, con o sin hipereosinofilia sanguínea periférica. $\mathrm{Su}$ asociación con síntomas alérgicos sistémicos, concentraciones elevadas de IgE y la respuesta al tratamiento con glucocorticoides en el 40-50\% de los casos sugieren la posible relación con reacciones alérgicas alimentarias $(1,4)$.

Presentamos el caso de varón de 40 años con antecedente hace 7 meses de cuadro de anafilaxia tras ingesta de rovellones, la situación se resolvió con corticoides y antihistamínicos sin ningún dato que sugiriera otra patología. Ingresa de nuevo y es intervenido de urgencia por presentar suboclusión intestinal con abdomen agudo. Se realiza resección segmentaria de íleon terminal que impresiona macroscópicamente de enfermedad de Crohn.

En las pruebas complementarias realizadas encontramos: parásitos en heces negativos, no eosinofilia en sangre, VSG 10, marcadores tumorales, autoanticuerpos e IgE normales, en la eco abdominal se aprecia distensión de asa de intestino delgado con edema de pared y en el TAC abdominal destaca vesícula biliar con pólipos de colesterol.

La anatomía patológica del segmento resecado nos muestra infiltrado inflamatorio eosinofílico de submucosa, muscular y serosa, sin signos de malignidad ni de enfermedad inflamatoria intestinal crónica.

Se distinguen tres formas de enteritis eosinofílica según la localización preferente del infiltrado, mucosa-submucosa (más común), muscular y serosa $(10 \%)(2,6,7)$.

Según la forma de afectación el cuadro clínico se caracteriza por naúseas, vómitos, diarreas, dolor abdominal, sind de malabsorción si se trata de la mucosa; cuadros de obstrucción intestinal incompleta si afecta a la muscular y ascitis exudativa con eosinofilia en la serosa $(1,2,4,7)$. El diagnóstico será de sospecha ante pacientes que presentan antecedentes alérgicos $(6,9)$, constituyendo el estudio histológico el pilar fundamental del diagnóstico (2). En un $30-65 \%$ de los casos se presenta como un abdomen agudo de difícil diagnóstico (8). Debemos descartar infestaciones parasitarias, linfangiectasia intestinal, Crohn y enfermedades del tejido conectivo. El pronóstico es favorable y en la mayoría de los casos en los que se consigue el diagnóstico de forma no invasiva el tratamiento consiste en la eliminación de determinados antígenos de la dieta y corticoides $(8,10)$. Sin embargo la extirpación del segmento afectado, en los casos de afectación del intestino delgado en forma de abdomen agudo, no cura la enfermedad, pues es un proceso que puede ser recidivante. A pesar de esto, la resolución sin secuelas de cada episodio es la norma $(4,6,10)$.

\section{Belenguer Carreras, E. Aguilar Cortés ${ }^{1}$, L. Cucurella Vidal, A. Cay Diarte ${ }^{2}$}

Servicios de Medicina Familiar y Comunitaria, ${ }^{\prime}$ Medicina Interna y de ${ }^{2}$ Anatomía Patológica. Hospital Comarcal. Alcañiz, Teruel

1. Álvarez García JF, Sánchez Sánchez MT, Chiquero Palomo M. Gastroenteritis eosinofílica: a propósito de dos casos. An Med Interna (Madrid) 2004; 21: 447-449.

2. Redondo Cerezo E, Moreno Platero JJ, García Domínguez E, González Aranda Y, Cabello Tapia MJ, Martínez Tirado P, et al. Presentación de gastroenteritis eosinofílica como brote de colitis con abdomen agudo. Gastroenterol Hepatol 2000 ; 23: 477-479.

3. Remacha Tomey B, Velicia Llames R, Del Villar A, Fernández Orcajo P, Caro-Patón Gómez A. Enteritis eosinofílica como causa de obstrucción intestinal. Gastroenterol Hepatol 1999; 22: 352-355.

4. Rodríguez Leal C, Tinoco Racero I, Téllez Pérez F, Girón González JA. Gastroenteritis eosinofílica. Medicine 2000; 08: 238-241.

5. Valderrama Rojas M, Cevallo Porras A, Pérez Tamayo. Abdomen agudo como forma de presentación de enteritis eosinofílica. An Med Interna (Madrid) 2001; 18: 450-451.

6. Gascón A, Talavera P, Sierra E. Enteritis eosinofílica complicada. Cirugía Española 2001; 69: 501-503.

7. Perea García J, Ots Gutiérrez JR, Martín Ruiz JR, Quijada García B Rodríguez Martín M, Francino Serrano J. Gastroenteritis eosinofílica como causa de obstrucción intestinal. Cirugía Española 2001; 69: 431-432.

8. Malaguarnera M, Restuccia N, Pistone G, Panebianco MP, Giugno I, Grasso G, et al. Eosinophilic Gastroenteritis. Eur J Gastoenterol Hepatol 1997; 9: 533-537.

9. Ruiz Montes F, Reñé Espinet JM, Rubio Caballero M. Gastroenteritis eosinofílica: revisión de los casos publicados en España y comparación con la literatura extranjera. Rev Esp Enf Ap Digest 1992; 81: 270-279.

10. De la Serna Higuera C, Rodríguez Gómez SJ, Martín Arribas MI. Gastroenteritis eosinofílica: espectro clínico de una misma entidad. An Med Interna (Madrid) 2002; 19: 361-364. 


\section{Neumonía como forma de debut de un condroma endobronquial}

\section{Sr. Director:}

El condroma es un tumor benigno pulmonar de origen mesenquimal, muy poco frecuente dentro del conjunto de los tumores pulmonares y más aún de los benignos, hasta el punto que en una amplia serie que incluyó 40.000 autopsias sólo se comunicaron 4 casos de condroma (1).

Presentamos el caso de un paciente afecto de condroma endobronquial que se puso de manifiesto tras un proceso neumónico y persistir una imagen patológica en la radiografía de tórax.

Varón de 58 años, alérgico a penicilina, diabético tipo 2 en tratamiento con sulfonilureas, ex-fumador de 20 paquetes/año, acudió a Urgencias por cuadro de una semana de evolución consistente en fiebre hasta $39^{\circ} \mathrm{C}$, tos con escasa expectoración y dolor pleurítico en hemitórax derecho. Había recibido tratamiento con claritromicina los 2 días previos sin mejorar. La radiografía de tórax mostró infiltrado alveolar en segmento apical de lóbulo inferior derecho (LID) con ligera pérdida de volumen del mismo, delimitando ambas cisuras. La gasometría arterial, hemograma, bioquímica, coagulación y ECG fueron normales. El paciente fue diagnosticado de neumonía extrahospitalaria de LID, iniciándose tratamiento con levofloxacino $500 \mathrm{mg} / 12$ horas durante 10 días, siendo remitido a consultas externas de Neumología. Las serologías respiratorias seriadas, antígeno de legionella y neumococo en orina y hemocultivos fueron negativos. Valorado al cabo de un mes había remitido la sintomatología pero persistía ligera tos irritativa. La radiografía de control mostró una imagen de aspecto seudonodular en segmento apical de LID que planteaba dudas con una atelectasia segmentaria residual. La TAC torácica y de abdomen superior mostró una atelectasia segmentaria en segmento 6 derecho, sin objetivar lesiones hiliares o parenquimatosas pulmonares ni adenopatías patológicas hiliares ni mediastínicas (Fig. 1). Se realizó una fibrobroncoscopia que mostró una tumoración exofítica, de superficie regular y blanquecina, no muy vascularizada en bronquio segmentario apical de LID que llegaba hasta la carina de división del bronquio de la pirámide basal. La biopsia bronquial fue informada como tumoración condral submucosa con cambio mucoide y atipia citológica ligera, que planteaba el diagnóstico diferencial entre condroma vs condrosarcoma de bajo grado. El paciente fue sometido a lobectomía inferior derecha y la anatomía patológica confirmó el diagnóstico de condroma. Actualmente sigue controles en nuestra consulta externa y se encuentra asintomático.

Existen muy pocas publicaciones en la literatura acerca de los condromas pulmonares, tratándose la mayoría, de casos aislados o series quirúrgicas cortas retrospectivas. En este sentido, en la serie quirúrgica de $\mathrm{Xu}$ y cols. se diagnosticó un caso en 17 años (2). En la serie de Regnard y cols., 5 pacientes presentaron condromas de un total de 208 tumores traqueales a lo largo de 23 años (3). En ocasiones son englobados de forma conjunta con los hamartomas, por lo que es difícil estimar su verdadera frecuencia (4). Es un tumor de lento crecimiento, más frecuente en varones que en mujeres con una proporción $2: 1$, con una media de edad en el diagnóstico entre 40 a 60 años (4). Puede ser intrabronquial o parenquimatoso, y dependiendo de su localización tendrá una distinta sintomatología, expresión radiológica y forma de diagnóstico.

Los condromas intrabronquiales, como en nuestro caso, son tumores que crecen invadiendo la luz bronquial, por lo cual van a producir principalmente síntomas de irritación de la vía aérea y obstrucción tales como tos, disnea, sibilantes o hemoptisis, expresándose radiológicamente como neumonitis postobstructiva, bronquiectasias o atelectasia. Debido a su comportamiento

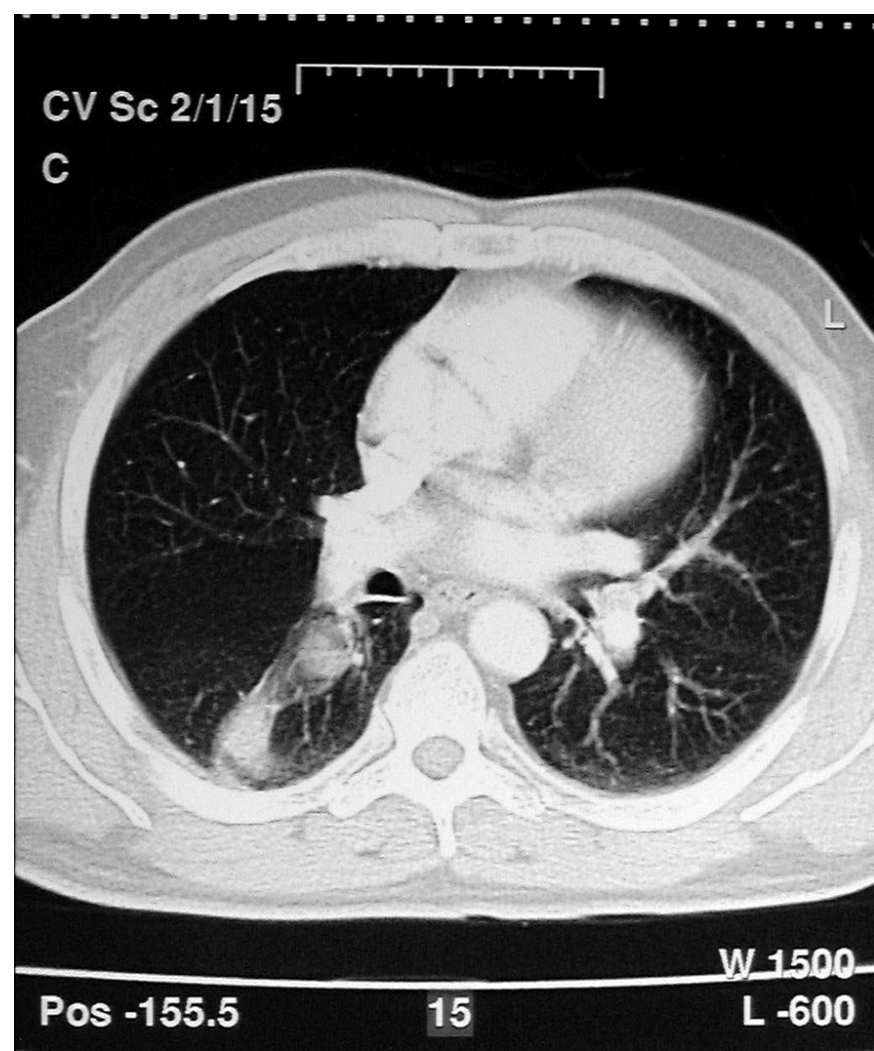

Fig. 1. TAC torácica que muestra imagen en huso con atelectasia segmentaria de $B 6$ derecho, correspondiente a condroma endobronquial.

endoluminal el diagnóstico puede realizarse mediante biopsia bronquial por fibrobroncoscopia. Crecen procedentes de los anillos bronquiales y son inseparables de la pared del bronquio, pudiéndose diferenciar perfectamente los anillos bronquiales cartilaginosos normales (1). Los intraparenquimatosos, por el contrario, cursan de forma asintomática y suelen ser un hallazgo casual en una radiografía de tórax adoptando la imagen de nódulo periférico. El diagnóstico en este caso se alcanza por PAAF o por resección quirúrgica de la lesión. Macroscópicamente son lesiones de 1-2 cm de tamaño, duros y blancos al corte, con áreas de calcificación y osificación. El diagnóstico diferencial con el hamartoma, condroblastoma o condrosarcoma en ocasiones es difícil (5). Endoscópicamente son tumoraciones exofíticas, poco vascularizadas y cubiertas de mucosa bronquial normal (6). La TAC es útil en el diagnóstico del condroma ya que permite valorar el estado del parénquima circundante, valorar la presencia de adenopatías mediastínicas y el patrón de calcificación. El tratamiento es siempre individualizado, dependiendo del tamaño, localización y estado del parénquima distal a la lesión. Se han empleado técnicas quirúrgicas como enucleación, broncotomía, lobectomía o neumonectomía y técnicas endoscópicas como resección local (7) o resección con láser neodymium-YAG (8). El pronóstico, al igual que el resto de tumores benignos es excelente. Puede recidivar si no se elimina totalmente y se han descrito casos de degeneración en condrosarcoma.

\section{E. Pastor, A. L. Andreu, M. Llombart, E. Chiner}

Servicio de Neumología. Hospital Universitario San Juan de Alicante 
1. Carter D, Eggleston JC. Bronquial condroma. En Carter D, Eggleston JC (eds): Tumors of the lower respiratory tract. Washington, Armed Forces Institute of Pathology 1980. p. 236-241.

2. Xu LT, Sun ZF, Li ZJ, Wu LH, Wang ZZ. Tracheobronchial tumors: an eighteen-year series from Capital Hospital, Peking, China. Ann Thorac Surg. 1983; 35: 590-6.

3. Regnard JF, Fourquier P, Levasseur P. Results and prognostic factors in resections of primary tracheal tumors: A multicenter retrospective study. J Thorac Cardiovasc Surg 1996; 111 :808-14.

4. Kaswin R, Hay JM, Brigand H, Merlier M. 71 pulmonary hamartochondromas. Poumon Coeur 1976; 32: 5-8.

5. Tarrazona V, Galán G, Monteagudo C. Condrosarcoma de traquea. A propósito de un caso. Arch Bronconeumol 1997;33: 481-482.

6. Vilas Iglesias A, Palacios Bartolomé A, Antúnez López J, Zamarrón Sanz C, Ledo Andión R, Rodríguez Suárez JR. Condroma endobronquial. An Med Interna (Madrid) 2003; 20: 387.

7. Lundgren R, Winblad B. Resection of bronchial chondroma through the flexible fiberoptic bronchoscope. Endoscopy 1980; 12: 81-2.

8. Eppinga P, van der Laan KT, Overbeek JJ, Meinesz AF, Postmus PE. Benign endobronchial tumours treated by neodymium-YAG laser. Eur Respir J 1998; 1: 568-70.

\section{Apoplejía pituitaria: ¿es una urgencia quirúrgica?}

\section{Sr. Director:}

La Apoplejía hipofisiaria ( $\mathrm{AH})$ es una entidad poco frecuente que se caracteriza por la aparición brusca de cefalea, vómitos, alteración de la conciencia, trastornos visuales y oftalmoplejía. Se produce por la expansión brusca de la hipófisis, debido a un infarto o una hemorragia de dicha glándula, habitualmente en presencia de un adenoma hipofisiario. En la mayoría de los casos son adenomas no secretores. Se piensa que hay algunos factores que pueden ser precipitantes de este síndrome, como la anticoagulación, la administración de bromocriptina, los traumatismos craneales, la irradiación hipofisiaria o la hipovolemia postparto (síndrome de Sheehan). El manejo adecuado de la AH es motivo de discusión, particularmente por la limitada experiencia y la gran variabilidad del curso clínico. La descompresión quirúrgica urgente ha sido una forma aceptada de tratamiento durante décadas. Presentamos un caso de AH que evolucionó favorablemente con tratamiento inicial conservador.

Varón de 55 años, con antecedentes de hipertrófia benigna prostática y ulcus duodenal, que consultó por un cuadro de cefalea fronto-orbitaria de predominio derecho de 2 días de evolución, junto a náuseas y diplopia en la mirada lateral derecha. En la exploración inicial destacaba una paresia del VI par derecho. A las 24 horas se añadió una parálisis del III par craneal del mismo lado. La agudeza visual y la campimetría fueron normales. La TAC craneal fue también normal, mientras que la RM mostró una masa en la silla turca, de diámetro máximo de $3,5 \times 2,5 \times 1 \mathrm{~cm}$, hiperintensa en T1 y T2, con señal heterogénea, extensión supraselar y compresión de ambos senos cavernosos (Fig. 1). Se inició tratamiento con altas dosis de esteroides $(200 \mathrm{mg} /$ día de hidrocortisona), y desapareció progresivamente la cefalea y la oftalmoparesia. A los 13 días del ingreso se realizó una resección transesfenoidal de la tumoración. El resultado anatomopatológico e inmunohistoquímico fue de adenoma hipofisiario con zonas de necrosis y negatividad para ACTH, FSH, LH, Prolactina, TSH y Sinaptofisina.

La AH tiene una baja mortalidad (aproximadamente del 5\%), pero requiere un alto grado de sospecha y un diagnóstico precoz. La edad media al diagnóstico oscila entre los 37 y los 57 años, dependiendo su sintomatología de las estructuras paraselares afectadas. La incidencia de este síndrome varía entre el 0,6\% y el

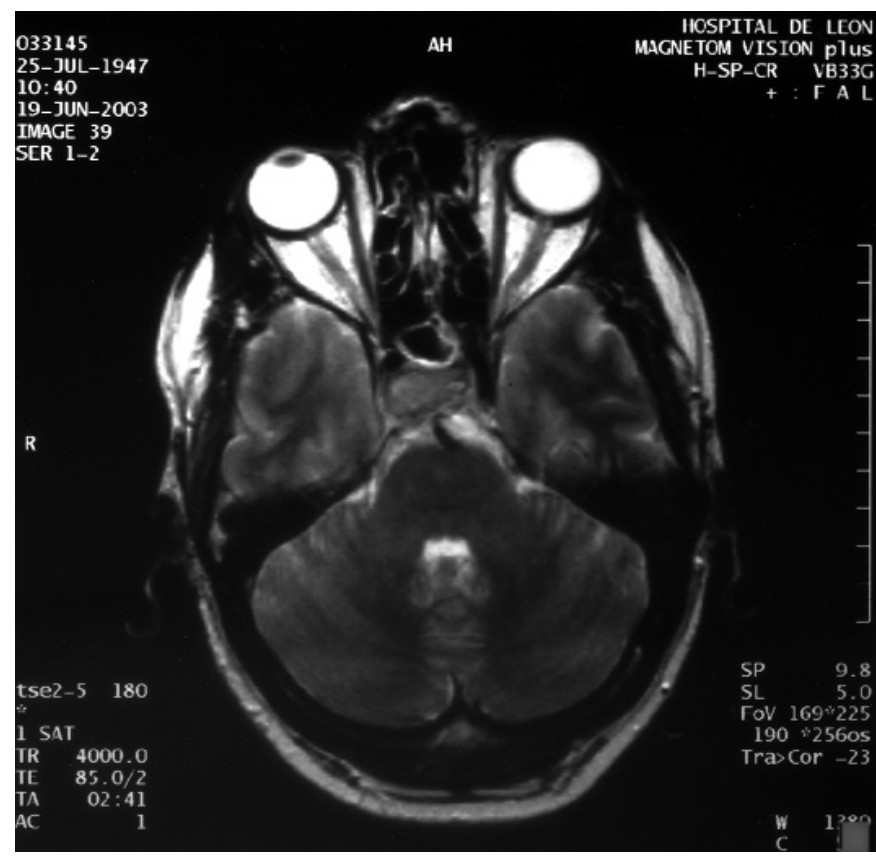

Fig. 1.

$10,5 \%$ de los adenomas hipofisiarios $(1,2)$. Sin embargo, en las series más amplias de adenomas tratados quirúrgicamente, se han encontrado hemorragias o infartos hasta en el $22 \%$ de los casos. Entre las pruebas de imagen, la RMN posee mayor sensibilidad que la TAC, tanto en el diagnóstico como en el seguimiento de la enfermedad (2-4). El hipopituitarismo transitorio o permanente es frecuente tras la $\mathrm{AH}$; por lo que un elevado número de pacientes requieren tratamiento hormonal sustitutivo. En relación al manejo óptimo de los episodios de apoplejía, la mayoría de los estudios parecen sugerir la descompresión quirúrgica precoz (en la primera semana), que no urgente, pero sólo en aquellos pacientes con importante deterioro visual, disminución del nivel de conciencia, o un curso clínico progresivo a pesar de tratamiento con esteroides $(5,6)$. Esto es así porque con frecuencia la evolución es favorable con tratamiento únicamente conservador (corticoides), fundamentalmente en aquellos casos que cursan con oftalmoparesia (7-9). En nuestro caso, el paciente siguió un curso óptimo tras tratamiento conservador en la fase aguda, lo cual apoya la observación anterior. Los grupos partidarios de cirugía a pesar de que haya una buena evolución con tratamiento médico, se basan en que, de esta manera, debido a una mejoría en la circulación hipotálamo-hipofisiaria, las alteraciones funcionales endocrinas de la fase aguda tienen mejor pronóstico y existe menor riesgo de recurrencia de apoplejía (10); de cualquier forma, esta hipótesis no ha sido confirmada por otros autores (7).

\section{Teijo Núñez, L. Hernández Echebarría ${ }^{1}$ E. Fernández Pérez, J. Tejada García ${ }^{1}$}

Servicios de Medicina Interna, $y^{\prime}$ Neurología. Hospital de Léon. León

1. Bills DC, Meyer FB, Laws ER, Davis DH, Ebersold MJ. A retrospective analysis of pituitary apoplexy. Neurosurgery 1993; 33: 602-609.

2. Randeva HS, Schoebel J, Byrne J, Esiri M, Adams CB, Wass JA. Classical pituitary apoplexy: clinical features, management and outcome. Clin Endocrinol (Oxf.) 1999; 51: 181-188.

3. Piotin M, Tampieri D, Rufenacht DA, Mohr G, Garant M, Del Carpio $\mathrm{R}$, et al. The various MRI patterns of pituitary apoplexy. Eur Radiol. 1999; 9: 918-923. 
4. García-Asensio S, Barrena R, Guelbenzu S, Guedea A, Mota J, Cacicedo Y. Magnetic resonance imaging usefulness in the diagnosis of intratumor bleeding in hypophyseal adenomas. Rev Neurol 1996; 24: 1237 1240.

5. Peter M, De Tribolet N. Visual outcome after transsphenoidal surgery for pituitary adenomas. Br J Neurosurgery 1995; 9: 151-157.

6. Cardoso ER, Peterson EW. Pituitary apoplexy: a review. Neurosurgery 1984; 14: 363-373.

7. Maccagnan P, Macedo CL, Kayath MJ, Nogueira RG. Conservative manegement of pituitary apoplexy: a prospective study. J Clin Endocrinol Metab 1995; 80: 2190-2197.

8. Mc Fadzean RM, Doyle D, Rampling R, Teasdale E. Pituitary apoplexy and its effect on vision. Neurosurgery 1991; 29: 675.

9. Chanson P, Lepeintre JF, Ducreux D. Management of pituitary apoplexy. Expert Opin Pharmacother 2004; 5: 1287-1298.

10. Fernández Real JM, Villabona CM, Montaña E. Apoplejía hipofisiaria: análisis de la función endocrina en 17 casos. Med Clin (Barc) 1991; 96 : 521-524.

\section{Piomiositis no tropical}

\section{Sr. Director:}

La piomiositis es una infección bacteriana aguda del músculo esquelético, más frecuente en climas tropicales, que ocasiona la formación de abscesos intramusculares. Aunque se puede presentar a cualquier edad es más frecuente que en climas tropicales afecte a niños de 5-9 años y adultos jóvenes, y en climas templados, a adultos de entre 20 y 40 años. Por sexos la relación es 2-3/1 a favor de los varones. Su incidencia está aumentando en los países occidentales, sobre todo en pacientes con enfermedades crónicas debilitantes como diabetes mellitus, enfermedades hematológicas, conectivopatías e infección por VIH (1-4). Recientemente hemos tenido la oportunidad de diagnosticar un caso de piomiositis del músculo obturador externo en un paciente joven inmunocompetente.

Se trataba de un varón de 20 años, sin antecedentes médicos de interés, que consultó por dolor inguinal tras actividad deportiva intensa que no cedía con reposo ni con antiinflamatorios no esteroideos, dificultándole la deambulación y sin que se pudiesen objetivar traumatismos ni heridas cutáneas. En la exploración física destacaba fiebre de $38,5{ }^{\circ} \mathrm{C}$, dolor a la movilización de la ingle derecha y adenopatías inguinales, recogiéndose pruebas complementarias como la analítica en la que se demostraba leucocitosis $\left(10.230 / \mathrm{mm}^{3}\right)$ con neutrofilia $(69 \%)$ y desviación izquierda (26\% Cay); la bioquímica, incluída la CPK y la coagulación eran estrictamente normales, con una VSG de $84 \mathrm{~mm}$ a la primera hora. En cuanto a las pruebas de imagen, concretamente la TAC pélvica evidenció ligero engrosamiento e hipodensidad del músculo obturador externo derecho respecto al contralateral, siendo sugestivo de piomiositis en fase inicial (Fig. 1). Los hemocultivos realizados fueron positivos para Staphylococcus spp., iniciándose tratamiento con vancomicina iv (1 g/12 h), que luego se fue sustituída por cloxacilina ( $2 \mathrm{~g} / 4$ horas) cuando se identificó el germen como Staphylococcus aureus meticilinsensible. La evolución del paciente fue tórpida con persistencia de la fiebre, quebrantamiento del estado general e incremento del dolor, evidenciándose en la TAC de control al cabo de cinco días extensión del proceso a la musculatura adductora ipsilateral y pequeñas zonas de abscesificación, por lo que se decidió abordaje quirúrgico. En la intervención quirúrgica, a pesar de que no se encontraron abscesos macroscópicos, se realizó limpieza de la zona tomándose muestras para estudio microbiológico, mostrando el cultivo del líquido drenado positividad para Staphylococcus aureus. A partir de entonces y continuando con la cobertura anti-

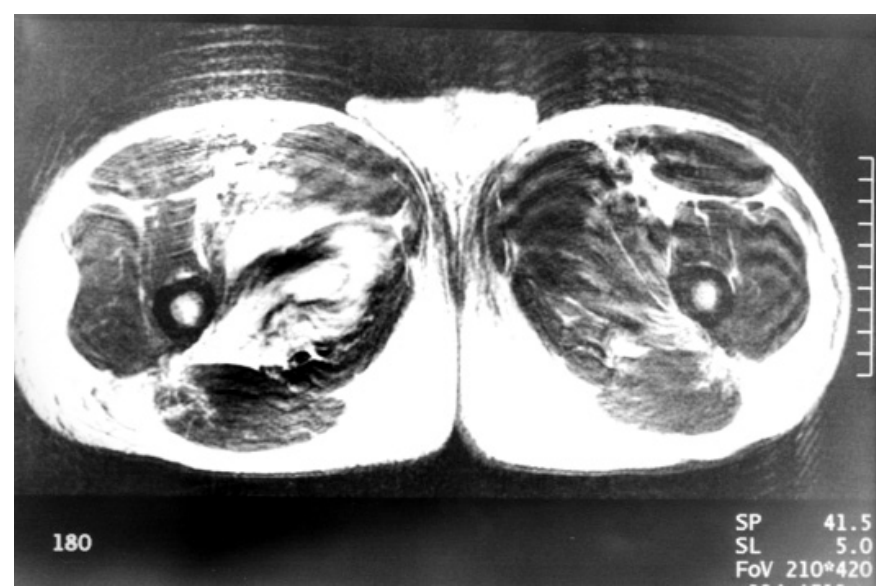

Fig. 1. Imagen hipodensa y heterogénea a nivel del músculo obturador externo derecho.

biótica anteriormente mencionada, la evolución fue favorable hasta la total resolución del cuadro clínico en el plazo de un mes.

Los agentes etiológicos más frecuentes responsables de piomiositis en nuestro medio son Staphylococcus aureus (70-90\%) y Streptococcus grupo B, C y G (Streptococcus pyogenes 5 a 15\%), aunque los hemocultivos son positivos sólo en el 5 al $30 \%$ de los casos $(1,2,5,6)$. Habitualmente, las manifestaciones clínicas suelen ser dolor, edema, fiebre e impotencia funcional, afectando generalmente a un solo grupo muscular con mayor frecuencia músculos de la celda anterior del muslo como el cuádriceps y de la cintura pélvica (1-4). El diagnóstico de sospecha es clínico y la prueba diagnóstica de elección es el TAC, consistiendo el tratamiento de primera línea en el drenaje del absceso, si lo hubiera, mediante cirugía o punción percutánea guiada por ecografía o TAC y tratamiento antibiótico intravenoso (7-10). A modo de conclusión, destacamos que a pesar de que la piomiositis es poco frecuente en nuestro medio, debería incluirse en el diagnóstico diferencial de aquellos pacientes que presenten fiebre, dolor muscular e impotencia funcional, especialmente en relación con enfermedades crónicas debilitantes y en sujetos que realizan ejercicio muscular intenso.

P. Barros Alcalde, R. López Rodríguez, F. L. Lado Lado, J. Campos Franco, R. Alende Sixto, I. Rodríguez Constenla

Servicio de Medicina Interna. Departamento de Medicina. Hospital Clínico Universitario de Santiago. Santiago de Compostela, A Coruña

1. Patel S R, Olenginski TP, Perruquet JL, Harrimgton TM. Pyomiositis: clinical features and predisposing conditions. J Rheumatol 1997; 24: 1734-8.

2. Merrien D, Hamidou M, Billaud E, Magadur G, Mussini JM, Raffi F. Bacterial pyomyositis. Analysis of 20 cases and review. Eur J Intern Med 1995; 6: 229-34.

3. Audran M, Masson C, Bregeon C, Varache N, Alquier P, Chennebault JM, Namour A, Caron C. Pyomyositis. Study of five cases and review. Rev Rhum English Ed 1993; 60: 49-54.

4. Christin L, Sarosi GA: Pyomyositis in Noth America: case reports and review. Clin Infect Dis 1992; 15; 668-77.

5. Levin MJ, Gardner P, Wladvogel FA. An unusualinfection due to Staphylococcus aureus. N Engl J Med 1971; 284: 196-8.

6. Gómez- Reino JJ, Aznar JJ, Pablor JL. Nontropical pyomyositis in adults. Semin Artth Rheum 1994; 23: 396-405.

7. Hossain A, Reis ED, Soundararajan K, Kerstein M, Hollier LH. Nontropical pyomyositis: analysis of eight patients in an urban center.Am Surg 2000; 66: 1064-6. 
8. Gómez Rodríguez N, Ferreiro Seoane JL, Ibáñez Ruán J, Lonjedo Vicent E. Piomiositis. Resolución con drenaje percutáneo y antibioticoterapia. Madrid: An Med Interna (Madrid) 1998;15; 560-1.

9. Gurbani SG, Cho CT, Lee KR, Powell L. Gonococcal abscess of the obturador internal muscle: use of new diagnostic tools may eliminate the need for surgical intervention. Clin infect Dis 1995: 1384-6.

10. Jiménez ME, Lozano M, Alfaro MJ, Fernández A, Jiménez C, Cañas E, Panchón J. Piomiositis por Staphylococcus aureus. Med Clin (Barc) 1992; 99: 201-5.

\section{Parálisis recurrencial izquierda y aneurisma de cayado aórtico}

\section{Sr. Director:}

El objetivo de este artículo es presentar un caso poco frecuente de parálisis recurrencial izquierda producida por un aneurisma aórtico.

La parálisis recurrencial izquierda puede ser la primera manifestación patológica que presente un paciente con patología cardiaca $(1,2)$ por lo que el conocimiento de esta complicación nos ayudará en el diagnóstico precoz de los aneurismas de aorta.

Se trata de un varón de 73 años con antecedentes de HTA, dislipemia, fibrilación auricular y doble lesión aórtica degenerativa leve, en estudio por disfonía de un mes de evolución sin otra sintomatología acompañante. En la exploración destaca parálisis de cuerda vocal izquierda sin alteraciones laríngeas y cardiomegalia de predominio izquierdo en la radiografía de tórax. Se realiza TAC torácico (Fig. 1) para descartar proceso neoproliferativo mediastínico que nos informa de masa de 31 × 34 × $35 \mathrm{~mm}$ en ventana aortopulmonar en íntima continuidad con arco aórtico con pequeñas calcificaciones periféricas que se rellena parcialmente de contraste, compatible con aneurisma sacular con trombo mural. Se confirma diagnóstico mediante aortografía torácica.

La parálisis recurrencial izquierda puede estar motivada por múltiples causas, siendo las neoplasias el origen más frecuente de parálisis, seguidas de traumatismos, infecciones, enfermedades neurológicas e idiopáticas (1). La etiología cardiovascular y en concreto los aneurismas de cayado aórtico son una causa rara de parálisis (2-6).

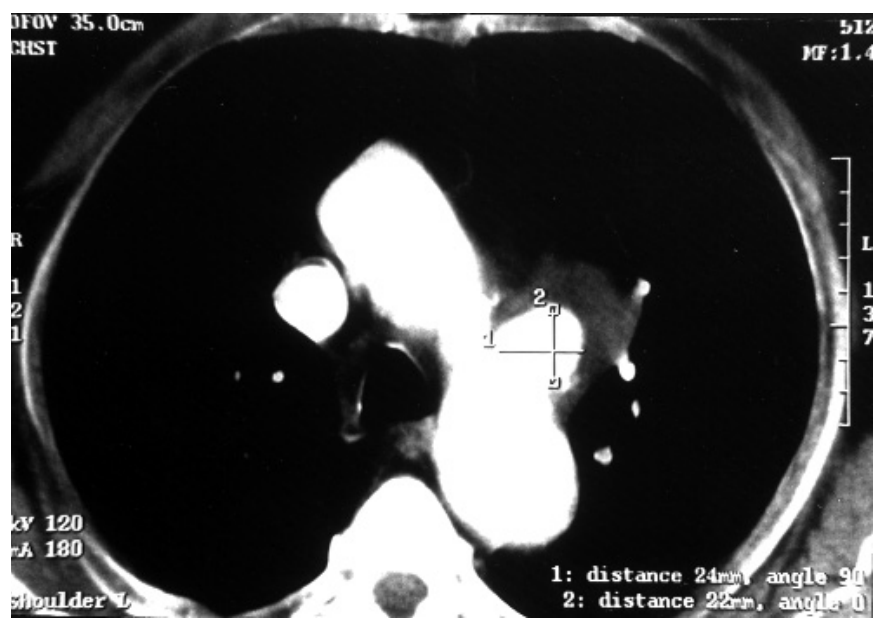

Fig. 1. TAC torácico: ocupación de ventana aorta-pulmonar por formación sacular que se rellena de contraste, en continuación con aorta sugestivo de aneurisma sacular con trombo mural.
El mecanismo por el cual se lesiona el nervio en los aneurismas de aorta torácica es por alargamiento-estiramiento del nervio o por compresión del nervio por el aneurisma $(3,7)$. La disfonía es un síntoma que se encuentra sólo en el $5 \%$ de los pacientes con aneurisma $(3,4)$.La parálisis recurrencial izquierda puede ser el primer signo de una enfermedad cardiovascular, descubriéndose la lesión cardíaca al explorar al paciente para realizar un diagnóstico diferencial de las causas de parálisis laríngeas $(2,6)$. Por lo que en todo paciente con disfonía de larga evolución debemos de pensar como posible causa en la existencia de aneurisma en cayado aórtico y el estudio radiológico torácico nos ayudará al diagnóstico precoz del aneurisma.

\section{Belenguer Carreras, M. P. Beguer Griñón, L. Cucurella Vidal, E. Aguilar Cortés ${ }^{1}$, M. I. Artigot Narro ${ }^{2}$}

Servicios de Medicina Interna, 'Medicina Familiar y Comunitaria. y de ${ }^{2}$ Radiodiagnóstico. Hospital Comarcal. Alcañiz, Teruel

1. Douglas D, Herbert H. Parálisis de las cuerdas vocales. En: Otorrinolaringología. Paparella MM, Shumrick, DA, Gluckman JL. Et Meyerhoff, W L, Buenos Aires: Ed. Panamericana, 1992. p. 109-110.

2. Del Cañizo Álvarez A, Del Cañizo Álvarez C, Taboada Mascarín T, et al. Parálisis recurrencial izquierda por enfermedad cardiaca o del cayado de la aorta. Acta Otorrinolaring Esp 1989; 40: 3: 167-172.

3. Martínez Sande JL, Amaro Cendón A, Blanco Labrador E, Pérez Rodríguez M. Parálisis del laríngeo recurrente izquierdo de etiología cardiovascular. Med Clin (Barc) 1992; 98: 158.

4. Teixido MT, Leonetti JP. Recurrent laryngeal nerve paralysis associated with thoracic aortic aneurysm. Otolaryngol Head Neck Surg 1990; 102 : 140-144.

5. Gupta KB, Tendon S, Yadav RK. Left vocal cord paralysis and aortic arch aneurysm: an unusual presentatio. Indian J Med Sci 2002; 56: $443-$ 4.

6. Thirlwall AS. Ortner's syndrome: a centenary review of unilateral recurrent laryngeal nerve palsy secondary to cardiothoracic disease. J Laryngol Otol 1997; 111: 869-71.

7. Ishimoto S, Ito K, Toyama M, Kawase I, Kondo K, Oshima K, Niimi S. Vocal cor paralysis after surgery for thoracic aortic aneurysm. Chest 2002; 121: 1911-5.

Necrosis avascular bilateral de cabeza femoral e infección por el virus de la inmunodeficiencia humana

\section{Sr. Director:}

En los últimos años se ha constatado un incremento de la necrosis avascular de cadera en los pacientes afectos de infección por el virus de la inmunodeficiencia humana (VIH) (1). La incidencia de osteonecrosis en la población infectada por el VIH es de $0,45 \%$, lo que viene a representar un incremento de unas 45 veces respecto a la población general (1). Incluso cuando se realizan estudios mediante técnicas de resonancia magnética en población asintomática infectada por el VIH, la incidencia de osteonecrosis asciende todavía más (2).

La importancia de las alteraciones metabólicas inducidas por la infección VIH o por los tratamientos concomitantes han sido una de las principales causas postuladas(3). También se ha relacionado con el tratamiento antiviral con inhibidores de la proteasa (4). 
Recientemente hemos tenido ocasión de diagnosticar un nuevo caso y nos parece interesante presentarlo brevemente a continuación.

Varón de 33 años, diagnosticado de infección por el VIH hacía 4 años. Entonces fue diagnosticado además de neumonía por Pneumocistis carinii y hepatopatía crónica por el virus de la hepatitis C. Era homosexual y no tenía antecedentes de adicción a drogas por vía parenteral. Los CD4 al diagnóstico fueron de 7 células $/ \mathrm{mm}^{3}$.

Tras recibir tratamiento adecuado, evolucionó de modo favorable, observándose una mejoría notable tanto inmunológica como virológica, siendo la carga viral indetectable a partir de los tres meses de comenzado el tratamiento.

Cuando consultó con nosotros seis meses más tarde recibía tratamiento antiviral con lamivudina, efavirenz y zidovudina, que era el primer y único régimen instaurado hasta entonces, así como profilaxis con trimetoprin-sulfametoxazol.

A los cuatro años del diagnóstico, fue enviado a las consultas externas de Traumatología al referir dolor en la región inguinal derecha de 6 meses de evolución, sin antecedente traumático No había tenido fiebre. La movilidad activa de la cadera era completa, aunque dolorosa.

En la radiografía de pelvis y axial de cadera se observaba una imagen sugestiva de necrosis avascular de la cabeza femoral derecha (Fig. 1A).

Se solicitó una RNM, objetivándose una necrosis avascular avanzada de la cabeza femoral derecha grado IV/IV de FICAT y datos de necrosis avascular de la cabeza femoral izquierda grado I-II/IV de FICAT.

Fue intervenido quirúrgicamente, implantándose sendos tornillos se tantalio (Fig. 1B).

El incremento en los diagnósticos de osteonecrosis de cadera puede no deberse a un aumento real de la incidencia, sino a la existencia de una mayor sensibilidad diagnóstica a consecuencia de la mayor atención que en la actualidad se presta a este problema y también a la aplicación de técnicas de mayor sensibilidad como la resonancia magnética nuclear (2).

En la mayoría de los casos la osteonecrosis se ha diagnosticado en pacientes jóvenes en estadios iniciales de la infección VIH, relacionándose con los efectos de la propia infección sistémica por el VIH (5).

La presencia de factores de riesgo para la osteonecrosis, tales como la hiperlipidemia, alcoholismo, pancreatitis e hipercoagulabidad es mayor que el grupo control (6).

Se ha observado una deficiencia de la proteína $C$, proteína $S$, antitrombina III y un aumento del factor Von Willebrand y del dímero D (7).

Los pacientes seropositivos además reciben tratamiento con corticoides, fundamentalmente en los casos de neumonía por Pneumocystis carinii, como en el caso que hemos presentado; postulándose un papel etiológico de éstos fármacos en la presentación del cuadro (8).

Una cuantificación de linfocitos CD4 inferior a $200 \mathrm{cel} / \mathrm{mm}^{3}$ ha sido asociado con un aumento de la frecuencia en la aparición de la

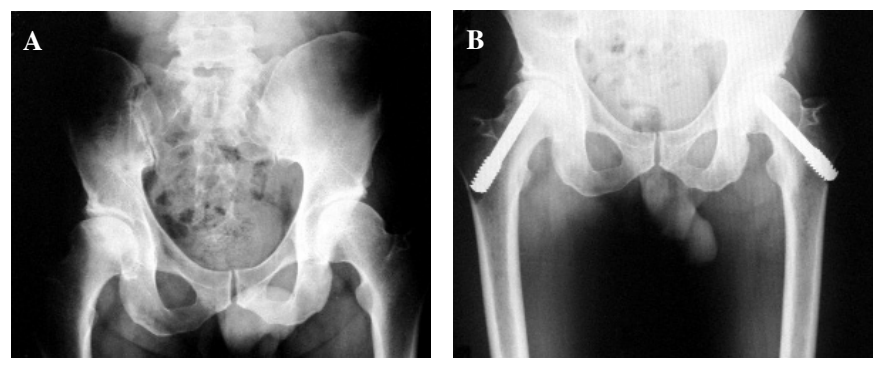

Fig. 1. A: Deformidad de ambas cabezas femorales con desestructuración de las mismas y áreas osteolíticas subcondrales, sugestivo de necrosis avascular; mucho más acusada en la cadera derecha; B: Se implantan tornillos de tantalio en ambas cabezas femorales. osteonecrosis, en el caso que hemos presentado los CD4 al diagnóstico fueron de 7 células $/ \mathrm{mm}^{3}$. La mejoría inmunológica secundaria al tratamiento antirretroviral de gran actividad, con el consiguiente incremento de los linfocitos CD4 también ha sido implicado en la aparición del cuadro de necrosis avascular de cadera (4).

Es necesario realizar periódicamente estudios radiográficos de cadera en pacientes afectos de la infección VIH para detectar de modo precoz la osteonecrosis.

Sin embargo la realización de RNM es el método que muestra una mayor sensibilidad para la detección precoz de la osteonecrosis avascular en pacientes de alto riesgo (9).

Con respecto al tratamiento, los mejores resultados se han obtenido con la implantación de prótesis totales y medidas locales coadyuvantes, si bien la decisión de la cirugía deberá estar en función de la existencia de un estado inmunitario aceptable (10).

\section{S. Casallo Blanco, J. A. Cano Palomares', F. Marcos Sánchez, D. Joya Seijo}

Servicios de Medicina Interna y de 'Traumatología. Hospital Nuestra Señora del Prado. Talavera de la Reina, Toledo

1. Brown P, Crane L. Avascular necrosis of bone in patient with human immunodeficiency virus infection: report of six cases and review of the literature. Clin Infect Dis 2001; 32: 1221-1226.

2. García-Álvarez García I, García-Álvarez García F, Crusels MJ, Cuesta Muñoz J, Letona Carbajo S, Amiguet García JA. Osteonecrosis y VIH. An Med Interna(Madrid) 2003; 20: 187-190.

3. Chevalier X, Larget-Piet B, Hernigou P, Cherardi R. Avascular necrosis of the femoral head in HIV-infected patients. J Bone Join Surg Br 1993; 75: 160 .

4. Monier P, McKnown K, Bronze MS. Osteonecrosis complicating highly active antiretroviral therapy in patients infected with human immunodeficiency virus. Clin Infect Dis 2000; 31: 1488-1492.

5. Rademaker J, Dobro JS, Solomon G. Osteonecrosis and human immunodeficiency virus infection. J Rheumatol 1997; 24: 601-604.

6. Scribner AN, Troia-Cancio PV, Cox BA, Marcantonio D, Hamid F, Keise p, et al. Osteonecrosis in HIV: a case control study. J Acq Immunodef Syndrome 2000; 25: 19-25.

7. Glueck CJ, Freiberg R, Tracy T, Stroop D, Wang P. Thrombophilia and hipofibrinolysis: pathophysiologies of osteonecrosis. Clin Orthop 1997 334: 43-56.

8. Blacksin MF, Kloser PC, Simon J. Avascular necrosis of bone in human immunodeficiency virus infected patients. Clin Imaging 1999; 23: 314-318.

9. Tervonen O, Mueller DM, Matteson EL, Velosa JA, Ginsburg WW, Ehman RL. Clinically occult avascular necrosis of the hip: prevalence in an asymptomatic population at risk. Radiology 1992; 182: 845-847.

10. Manzaneque González L, Mayoral Martín L, Jiménez Ocaña C, Corzo Delgado JE, Sánchez-Matas Rodríguez P, Grilo Reina A. Necrosis avascular bilateral de cabeza femoral en un varón VIH positivo. An Med Intern (Madrid) 1994; 11: 601-603.

Fiebre de origen desconocido como forma de presentación de la disección aórtica crónica

\section{Sr. Director:}

La disección de aorta (DA) es una enfermedad grave, con una mortalidad elevada (1). El síntoma más frecuente es un dolor torácico severo y agudo (más del 90\%) (2). La DA se acompaña de fiebre en aproximadamente un tercio de los casos no obstante la fiebre de origen desconocido (FOD) como manifestación principal de la DA es extremadamente rara. En nuestro caso y otros revisados en la literatura en los que la DA se manifiesta como FOD la fiebre domina el caso clínico estando acompañada de 
sudores nocturnos, pérdida de peso y ausencia o presencia de escaso dolor. El conocimiento de esta forma inusual de presentación puede permitir su diagnóstico.

Aportamos el caso de un varón de 57 años de edad, fumador, hipertenso, dislipémico y con un infarto inferior hace 11 años. El día del ingreso presentó un dolor prolongado en epigastrio irradiado a precordio acompañado de un cuadro vegetativo con alteraciones dinámicas del ST en cara antero-lateral. Se trasladó a la UCI con diagnóstico de síndrome coronario agudo, instaurándose tratamiento con nitratos, enalaprilo, ácido acetilsalicílico, clopidogrel y heparina de bajo peso molecular. El paciente permaneció asintomático y se trasladó de nuevo a planta realizándose un ecocardiograma donde se evidenció hipertrofia de ventrículo izquierdo y aquinesia inferobasal. En la radiografía se observó una aorta elongada de aspecto aneurismático que ya existía en una radiografía realizada cuatro años antes. A los tres días del ingreso, comenzó con fiebre que continuó durante tres semanas junto a una mínima perdida de peso, sin volver a presentar dolor torácico. En la analítica destacaba anemia normocitica $11 \mathrm{~g} / \mathrm{dl}$ y una VSG de $86 \mathrm{~mm}$ estando el resto de los parámetros analíticos dentro de la normalidad. Se solicitaron hemocultivos que fueron estériles, serología para brucella, fiebre Q, citomegalovirus, virus Epstein-Barr, HIV que fueron negativas, gastroscopia y sangre oculta en heces que es normal, se realizó un mantoux siendo éste positivo. En la tercera semana del ingreso, con motivo del estudio de una FOD y por la existencia de una aorta aneurismática se solicitó una TAC toraco-abdominal en la que se detectó una dilatación aneurismática de la aorta descendente distal al origen de la subclavia con diámetro máximo de $49 \mathrm{~mm}$ e imagen de doble luz sugerente de DA tipo B así como dilatación aneurismática de aorta abdominal que en su porción infrarrenal es de $59 \mathrm{~mm}$ (Fig. 1). Se realizó un ecocardiograma en el que se comprobó la integridad de la aorta ascendente y el cayado. Se remitió al enfermo al Servicio de Cirugía Vascular decidiéndose tratamiento conservador.

La FOD continúa siendo un desafío diagnóstico en la práctica clínica. Las causas son múltiples, estando incluída la DA como una de ellas. La DA puede presentarse como una enfermedad sistémica con fiebre prolongada de bajo grado asociada a anorexia y pérdida de peso. Los pacientes normalmente son hombres hipertensos en la sexta o séptima década de la vida aunque en ocasiones no hay factores predisponentes. Puede existir dolor torácico, de espalda y de abdomen, pero en otros casos el dolor no existe, es de baja intensidad o cede espontáneamente. En nuestro caso el dolor fue inicial dominando luego la fiebre el cuadro clínico. La ausencia de dolor y la fiebre persistente muchas veces desorienta al clínico lo que retrasa el diagnóstico (3).

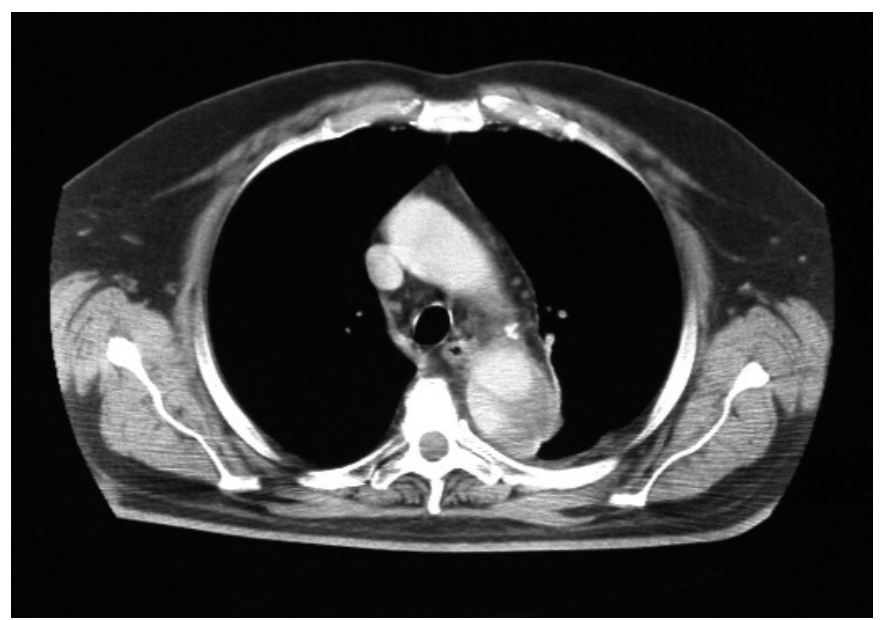

Fig. 1.
La DA se acompaña de fiebre en un tercio de los pacientes pero la FOD como manifestación predominante de la disección de aorta es extremadamente rara, en la literatura médica sólo hay una serie de once casos (4), el resto de los artículos son casos aislados (5). El mecanismo por el cual la DA produce fiebre no se conoce completamente (6). En algunos casos está causada por un infarto de órganos vitales o por una pericarditis hemorrágica. Se ha sugerido que el hematoma por sí mismo puede resultar pirógeno.

Tanto la fiebre como las otras manifestaciones sistémicas se pueden dar en otras enfermedades de la aorta, que es importante excluir como el aneurisma aórtico infectado, la trombosis mural y la enfermedad de Takayasu y la arteritis de la temporal. Las pruebas diagnósticas más útiles son el TAC, la RNM y el ecocardiograma transesofágico dada su alta sensibilidad y especificidad $(7,8)$.

M. D. Joya Seijo, P. del Valle Loarte, S. Arenas Sotelo, F. Marcos Sánchez, P. Rodríguez Ballestero

Servicios de Medicina Interna y Cardiología. Hospital Nuestra Señora del Prado. Talavera de la Reina, Toledo

1. Khan IA. Clinical Manifestations of aortic dissection. J Clin Basic Cardiol 2001; 4: 265.

2. Spittell PC, Spittell JA Jr, Joyce JW, Tajik AJ, Edwards WD, Scaff HV Stanson AW. Clinical features and differential diagnosis of aortic dissection: experience with 236 cases (1980 through 1990). Mayo Clinic Proc 2002; 77: 296.

3. Giladi M, Pines A, Averbuch M, Hershkoviz R, Sherez J, Levo Y. Aortic dissection manifested as fever of unknown origin. Cardiology 1991; 78: $78-80$

4. Schattner A, Kelpfish A, Caspi A. Chronic aortic dissection presenting as a prolonged febrile disease and arterial embolization. Chest 1996; 110: 1111-4.

5. De Rivas Otero B, Solano Cebrián MC, López Cubero L. Fiebre de origen desconocida y disección aórtica. Rev Clin Esp 2003; 203: 507-508.

6. Mackowiak PA, Lipscomb KM, Mills LJ, Smith SW. Dissecting aortic aneurysm manifested as fewer of unknown origin. JAMA 1976; 236: 1725-27.

7. Cigarroa JE, Isselbacher EM, De Sanctis RW. Diagnostic imaging in the evaluation of suspected aortic dissection. N Engl J Med 1993; 328: 35-43.

8. Nienaber CA, Von Kodolitsch Y, Nicolas V. The diagnosis of thoracic dissection by noninvasive imaging procedures. N Engl J Med 1993; 328: 1-9.

Evaluación del cumplimiento de dos protocolos del tratamiento de la neumonía adquirida en la comunidad, por el Servicio de Medicina Interna y la Unidad de Neumología

\section{Sr. Director:}

La realización de protocolos para el tratamiento y seguimiento de procesos clínicos prevalentes, tiene ventajas dado que permite encuadrar la actuación médica disminuyendo la variabilidad, reduciendo los errores y permitiendo de este modo una mejor defensa legal si las circunstancias lo requirieran, pero también tienen inconvenientes como la indudable pérdida de tiempo que condiciona su cumplimiento dado que a veces son difíciles o laboriosos en su aplicación; además frecuentemente existe una falta de consenso en su elaboración, dado que no están diseñados por todos los profesionales implicados en la patología protocolizada. A menudo la difusión de los mismos es escasa y ni tan siquiera algunos miembros de los servicios implicados los cono- 
cen. Otro teórico inconveniente es que algunos facultativos pueden considerarlo como una cierta imposición a la libre práctica médica por parte de los órganos de gobierno, además no existe ninguna recompensa por su correcto cumplimiento ni penalización alguna por su incumplimiento y finalmente en la mayoría de los casos ni siquiera se evalúa su adecuada aplicación, por lo que no hay datos concretos que nos permitan apoyar su práctica habitual.

Hay diversas patologías muy prevalentes en el ámbito hospitalario que están protocolizadas incluso en ocasiones por varios servicios a la vez que pueden tratar a los pacientes afectos del citado proceso y diseñan protocolos habitualmente diferentes.

Por parte de la comisión de infección hospitalaria, profilaxis y política antibiótica de nuestro centro, se decidió evaluar el cumplimiento del protocolo de neumonía adquirida en la comunidad, en los casos que precisaban ingreso en el hospital, al tratarse de neumonías graves, realizado por los Servicios de Medicina Interna y de Neumología y que tenían aceptados, los citados protocolos no eran idénticos, aunque evidentemente eran muy semejantes en esta patología en la que habitualmente no andamos escasos de protocolos y guías clínicas (1-4).

Los criterios para definir neumonía grave y factores de riesgo de etiología no habitual eran los mismos en los dos protocolos y seguían las recomendaciones generales sobre esta patología.

El protocolo de Neumología recomendaba en los casos de neumonía grave, sin riesgo para etiología no habitual, ceftriaxona a dosis de 2 gramos día por vía intravenosa y en los casos de sospecha de existencia de Legionella pneumophila se asociaba además claritromicina a dosis de 500 miligramos cada 12 horas por vía oral o intravenosa. En los casos de neumonía grave y sospecha de etiología no habitual, el tratamiento consistía en la asociación de ceftriaxona y claritromicina a las mismas dosis que las referidas anteriormente.

El protocolo de Medicina Interna recomendaba en los casos de Neumonía grave sin la existencia de factores de riesgo para una etiología no habitual, tratamiento con ceftriaxona a dosis de 2 gramos al día o cefotaxima a dosis de 1 gramo cada 6 horas, asociadas a claritromicina a dosis de 500 miligramos cada 12 horas. Como segunda opción, pero también válida aceptaba el tratamiento con levofloxacino a dosis de 500 miligramos cada 12 ó 24 horas. En los casos de neumonía grave y sospecha de etiología no habitual recomendaba como primera opción un tratamiento con ceftriaxona o cefotaxima, siempre asociados a un macrólido y como segunda opción, y también válida levofloxacino a las dosis referidas anteriormente. En los casos de sospecha de aspiración recomendaba realizar tratamiento con levofloxacino asociado a clindamicina a dosis de 600 miligramos cada 6 horas o piperacilina/ tazobactan en monoterapia a dosis de 4 gramos cada 8 horas y como segunda opción la asociación de ceftriaxona o cefotaxima junto a claritromicina y clindamicina.

Se evaluó el cumplimiento del protocolo de tratamiento de 45 neumonías graves en adultos, se consideraron tratamientos correctos siguiendo el protocolo de Neumología 6 casos (13\%) y respecto al tratamiento recomendado por Medicina Interna, cumplían 20 casos (44\%).

Analizando el porqué de este escaso cumplimiento, podemos decir que Neumología en el protocolo diseñado no contemplaba el tratamiento con quinolonas en los casos de neumonías graves, siendo sin embargo uno de los antibióticos más utilizados por dicho servicio. La conclusión que se puede extrapolar de esta información es que el protocolo se debería haber actualizado, incluyendo el levofloxacino como opción válida, dado que es una práctica adecuada.

Ambos servicios no aceptaban en sus protocolos la utilización de amoxicilina/ácido clavulánico, como primera o segunda opción para el tratamiento de las neumonías graves, sin embargo era uno de los antibióticos más utilizados por ambos servicios, incluso en los casos en lo que no existía sospecha de aspiración pulmonar, situación esta en la que debería haberse considerado dicho tratamiento como una opción válida.

Las conclusiones de nuestro estudio demuestran una vez más que el cumplimiento de los protocolos por parte de los servicios implicados es muy escaso. Otros aspectos a considerar, son que al tratarse de un hospital del grupo 2 no existen guardias exclusivas de Neumología y de Medicina Interna y por lo tanto los ingresos los podían efectuar otros especialistas que indicaban el tratamiento que les parecía conveniente y luego si la evolución había sido favorable, no resulta frecuente que se proceda a un cambio de tratamiento en los casos en los que la terapia inicial fuera aceptable, aunque no estuviera incluida en los protocolos del servicio, lo que afectaba a la mayoría de los casos analizados.

\section{F. Marcos Sánchez, J. Celdrán Gili ${ }^{1}$ A. Biurrún Larralde², F} Árbol Linde ${ }^{3}$, C. Iranzu Aperte ${ }^{4}$, L. Caballero Sánchez-Robles ${ }^{5}$

Servicios de Medicina Interna, ${ }^{\prime}$ Neumología, ${ }^{2}$ Medicina Preventiva y Coordinadora de Calidad, ${ }^{3}$ Cuidados Intensivos, ${ }^{4}$ Farmacia Hospitalaria y ${ }^{5}$ Microbiología. Hospital Nuestra Señora del Prado. Talavera de la Reina, Toledo

1. Sociedad Española de Neumología y Cirugía Torácica (SEPAR). Diagnóstico y tratamiento de la neumonía adquirida en la comunidad. Arch Bronconeumol 1997; 33: 240-246.

2. Barlett JG, Mundy LM. Community-acquired pneumoniae. N Engl J Med 1995; 333: 1618-1624.

3. British Thoracic Society Guideline for the management of communityacquired pneumoniae in adults admitted to hospital. Br J Hosp Med 1993; 49: 346-350.

4. American Thoracic Society. Guidelines for the initial management of adults with community-acquired pneumonia: diagnosis, assessment of severity and initial antimicrobial therapy. Am Rev Respir Dis 1993 148: $1418-1426$

\section{Hemartros espontáneo inducido por dicumarínicos}

\section{Sr. Director:}

El hemartros espontáneo por dicumarínicos es un problema clínico poco usual. La incidencia de hemartros como complicación de anticoagulación oral (ACO) varía de 0 a 1,5\% (1). Ocurre habitualmente en articulaciones grandes, como rodillas y hombros $(2)$, generalmente con patología preexistente $(3,4)$ (artropatía cristalina, inflamatoria, degenerativa). Otro factor de riesgo sería la toma simultánea de fármacos que potenciaran la acción anticoagulante de los dicumarínicos, como los AINE, alopurinol, esteroides anabólicos, andrógenos, ciertos antiarrítmicos y antibióticos $(3,5)$.

Presentamos el caso de un varón de 80 años de edad con antecedentes de hiperuricemia con episodios de monoartritis aguda desde hace años en metatarsofalángica del primer dedo de ambos pies, rodillas, muñecas y hombro derecho. Diagnosticado de miocardiopatía dilatada en fibrilación auricular y cuadros de fallo de ventrículo izquierdo, llevando a cabo tratamiento con alopurinol, aldactone, furosemida, digoxina y dicumarínicos.

Acudió por cuadro de 24 horas de evolución, sin antecedente traumático, de dolor e impotencia funcional en hombro izquierdo. En la exploración destacaban signos de inflamación en hombro izquierdo con limitación a la abducción y elevación y pequeña equimosis a dicho nivel. 
La analítica general era normal a excepción de una proteína $\mathrm{C}$ reactiva (PCR) de $17 \mathrm{mg} / 1 \mathrm{y}$ un estudio de coagulación con tasa de complejo protrombínico (TP) del 18\% con un INR 3,04.

Se realizó estudio con resonancia magnética nuclear (RMN) de hombro izquierdo objetivando marcado derrame articular que distiende de forma severa la articulación glenohumeral con líquido intrarticular demostrando una señal alta y afectación heterogénea (Fig. 1). Se realizó punción de la articulación obteniendo 20 cc de líquido hemorrágico, con determinación para cristales y estudio microbiológico negativo. Se suspendieron los dicumarínicos y se inició HBPM llevando a cabo tratamiento rehabilitador con excelente evolución.

La forma habitual de presentación del hemartros es la monoartritis aguda $(1,6)$. El dolor y la impotencia funcional de la articulación afecta son los síntomas primordiales. En la exploración física destacan los signos de inflamación: calor, eritema, hinchazón y dolor a la palpación que aumenta con la movilidad. La equimosis cutánea en ausencia de traumatismo previo puede orientar el diagnóstico. El líquido sinovial (3) obtenido en la artrocentesis es de aspecto hemático, con niveles de glucosa similares a la glucemia plasmática, cultivos y búsqueda de microcristales negativos. Una tasa de protrombina disminuída no supone una contraindicación para el aspirado articular. En cuanto a las técnicas de diagnóstico por imagen $(7,9)$, la radiografía simple de la articulación puede ser normal, mostrar un estado edematoso de partes blandas, o evidenciar alguna enfermedad articular previa, ayudándonos a descartar otros diagnósticos. La RMN no es una técnica de rutina pero puede emplearse para el estudio de articulaciones profundas, como el hombro.

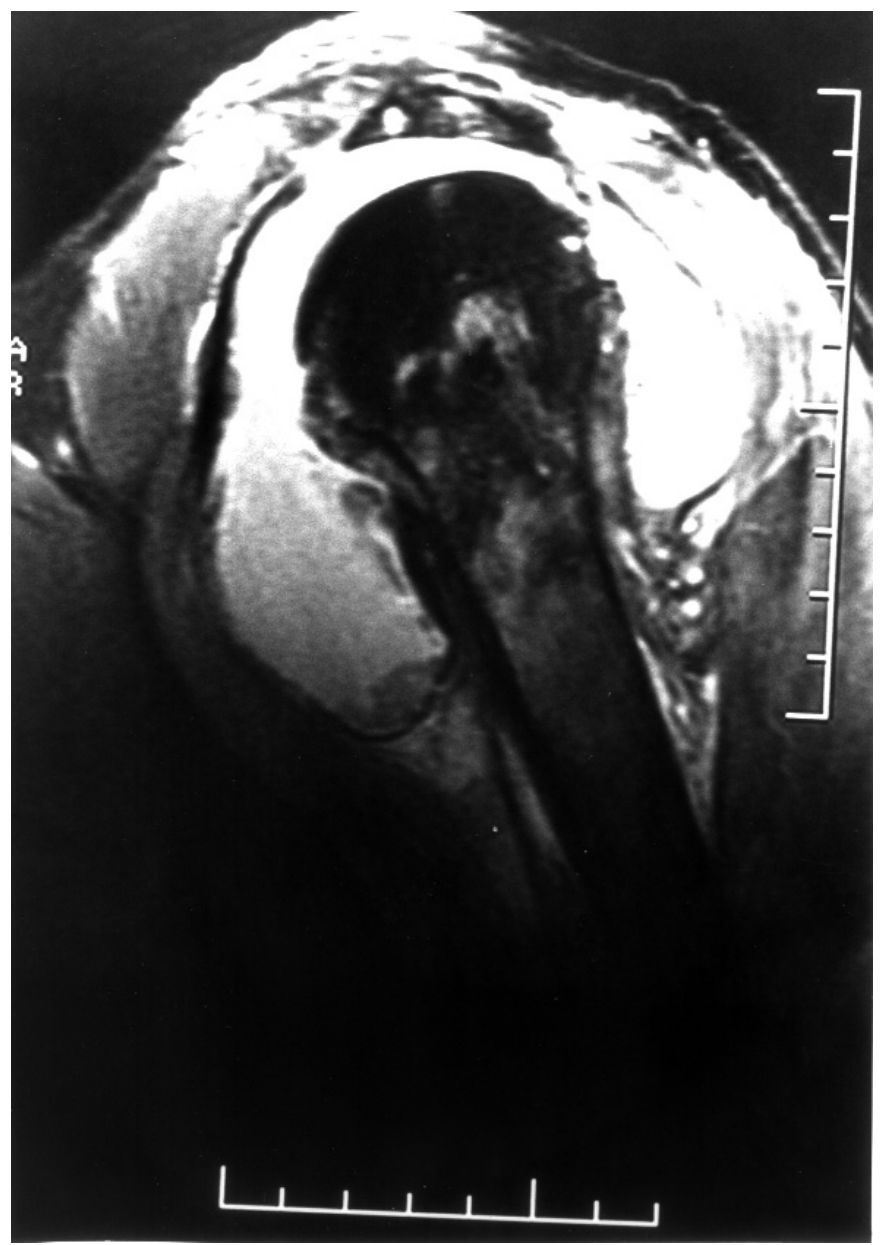

Fig. 1. RMN: Marcado derrame en articulación glenohumeral.
El diagnóstico diferencial que debemos plantearnos ante un hemartros espontáneo incluye las siguientes entidades (3): deficiencias hereditarias de factores de la coagulación, anemia falciforme, crisis de pseudogota, amiloidosis, sinovitis vellonodular pigmentada, hemangioma sinovial, artritis reumatoide, neoplasia metastásica articular, enfermedad mieloproliferativa, vasculitis, coagulopatía farmacológica (por toma de dicumarínicos, como es nuestro caso).

El tratamiento se basa en la analgesia, aspiración-evacuación del derrame, y disminución o suspensión de la anticoagulación oral (3). La evolución y pronóstico una vez normalizado el TP son buenos, puesto que el hemartros por ACO no suele provocar artropatía como secuela a diferencia del hemartros crónico o el que aparece con frecuencia en pacientes hemofílicos.

Una monoartritis aguda en paciente anticoagulado y en ausencia de traumatismo previo nos hará considerar el hemartros espontáneo inducido por dicumarínicos en el diagnóstico diferencial.

\section{Galiana Martín, F. J. Nuño Mateo, J. Noval Menéndez, M. J. Menéndez Calderón}

Servicio de Medicina Interna. Hospital de Cabueñes. Gijón

1. George E, McLaughlin MD, Daniel J, McCarty Jr MD, Bernard L, Segal MD. Hemarthrosis complicating anticoagulant therapy. Report of three cases. JAMA 1966; 166; 11: 202-3.

2. Riley SA, Spencer GE Jr. Destructive monoarticular arthritis secondary to anticoagulant therapy. Clin Orthop 1987; 223: 247-51.

3. Wild JH, Zvaifler NJ. Hemarthrosis associated with sodium warfarin therapy. Arthritis Rheum 1976; 19 (1): 98-102.

4. Gerster JC, Wauters JP, Waldburger M, Saudan Y. Hemarthroses complicating anticoagulant therapy (heparin and oral anticoagulants). Schweiz Med Wochenschr 1977; 107 (33): 1170-2.

5. Howard PA, Ellerbeck EF, Engelman KK, Patterson KL. The nature and frecuency of potential warfarin drug interactions that increase the risk of bleeding in patient with atrial fibrillation. Pharmacoepidemiol Drug Saf 2002; 11 (7): 569-76.

6. Canoso JJ. Acute monoarthritis. N Engl J Med 1993; 30: 329 (14): 1013-20.

7. Till SH, Snaith ML. Assesment, investigation, and management of acute monoarthritis. Accid Emerg Med 1999; 16: 355-361.

8. Scutellari PN, Orzincolo C, Castaldi G, Franceschini F. Monoarthritis. Radiol Med (Torino) 1995; 90 (6): 689-98.

9. Ben Salem SA. MRI as a diagnostic technique in examination of the shoulder joint. Vestn Rentgenol Radiol 2002; (5): 23-8.

\section{Colitis linfocitaria inducida por carbamacepina}

\section{Sr. Director:}

La carbamacepina es un fármaco utilizado con frecuencia en diversos trastornos como la epilepsia generalizada y parcial, neuralgia del trigémino, trastorno bipolar e hipercinesia paroxística entre otros. Los efectos secundarios más frecuentes son los que afectan al sistema nervioso; los efectos gastrointestinales se presentan en un $0-9 \%$ de los casos, y habitualmente son de carácter leve, cediendo con el tiempo, por lo que no suele ser necesaria la suspensión del fármaco (1). Describimos el caso de un paciente que desarrolló un cuadro de diarrea crónica secundaria a colitis linfocitaria (CL) durante el tratamiento con carbamacepina y que remitió tras la retirada del fármaco. 
Presentamos el caso de un varón de 54 años que ingresa con cuadro de diarrea de tres meses de evolución. En sus antecedentes personales destacaba el diagnóstico de epilepsia generalizada primaria desde la infancia. El paciente cuatro meses antes del ingreso estaba en tratamiento con ácido valproico $(500 \mathrm{mg} / 8 \mathrm{hs})$ y topiramato (100 $\mathrm{mg} / 12 \mathrm{hs)} \mathrm{desde} \mathrm{hacía} \mathrm{dos} \mathrm{años.} \mathrm{Debido} \mathrm{al} \mathrm{mal} \mathrm{control} \mathrm{de} \mathrm{la} \mathrm{epilep-}$ sia se inició tratamiento con carbamacepina en pauta ascendente hasta $200 \mathrm{mg} / 8$ hs en sustitución del topiramato. La epilepsia mejoró pero a las seis semanas del comienzo de la carbamacepina el paciente inicia cuadro de diarrea con 5-7 deposiciones diarias líquidas, acompañadas de retortijón, sin moco, sangre o pus; lo que motiva su ingreso. A su llegada al hospital no tenía fiebre y refería haber perdido $5 \mathrm{~kg}$ de peso. En la exploración el abdomen era blando, depresible, con aumento de ruidos hidroaéreos, sin masas ni megalias y no doloroso a la palpación. El resto de la exploración física era normal. En sus antecedentes familiares no había historia de enfermedad celiaca, enfermedad inflamatoria intestinal o poliposis y no había sido tratado con ningún otro fármaco.

Los estudios analíticos realizados: hemograma, VSG, bioquímica general con hormonas tiroideas, coagulación, metabolismo del hierro, vitamina B12 y ácido fólico y prueba de D-xilosa fueron normales y no se encontraron datos de malabsorción. Los niveles séricos de carbamacepina y ácido valproico eran de 7,16 $\mathrm{mg} / \mathrm{l}(6-12)$ y $55,60 \mathrm{mg} / \mathrm{l}(50-100)$ respectivamente. Las serologías para bacterias, parásitos entéricos y virus fueron negativas. El enema opaco y tránsito gastrointestinal resultaron normales y el examen parasitológico y cultivo de heces fueron negativos. En la colonoscopia se observaron hemorroides internas de primer grado, sin otros datos. Se obtuvieron biopsias a varios niveles; en el estudio de la biopsia del colon se observó un aumento de células inflamatorias crónicas a nivel de la lámina propia a expensas de linfocitos, eosinófilos y células plasmáticas que también producían infiltración de estructuras glandulares, observándose un incremento de linfocitos intraepiteliales. La carbamacepina fue sustituida por gabapentina ( $400 \mathrm{mg} / 8 \mathrm{hs}$ ) desapareciendo la diarrea a los siete días. El paciente fue dado de alta y ante la recurrencia de las crisis, a los veinte días, reinició por su cuenta tratamiento con carbamacepina reapareciendo la diarrea tras dos dosis de $200 \mathrm{mg}$, desapareciendo la misma tras la nueva retirada del fármaco. Actualmente la epilepsia está bien controlada con la asociación de ácido valproico y oxcarbacepina.

La colitis linfocitaria es un síndrome clínico-patológico infrecuente caracterizado por diarrea crónica acuosa, cambios inflamatorios difusos en la mucosa colónica, a pesar de la normalidad en las exploraciones radiológicas y endoscópicas, y alteraciones microscópicas consistentes en aumento del número de linfocitos intraepiteliales (2). La etiología de la CL es desconocida, aunque se ha sugerido un origen autioinmune basándose en datos inmunopatológicos que indican activación crónica de linfocitos $\mathrm{T}$ contra antígenos expresados en las células epiteliales (3) y en la asociación con otras enfermedades autoinmunes (artritis reumatoide, hipo- hipertiroidismo, anemia perniciosa, fibrosis pulmonar idiopática, púrpura trombocitopénica idiopática, alopecia areata y diabetes melitus juvenil). El cuadro suele comenzar en la sexta década de la vida, afecta por igual a ambos sexos y aunque se han utilizado diversos fármacos (corticoides, antiinflamatorios no esteroideos...) no hay un tratamiento definido. En raras ocasiones se ha descrito la CL asociada a fármacos como "Ciclo 3 Fort" (flebotónico) (3), ranitidina (4) y ticlopidina (5). Esta asociación ha sido demostrada en algunos casos al encontrar alteraciones microscópicas en la mucosa colónica y su normalización tras la retirada del fármaco responsable. Además, la reintroducción del fármaco, como en nuestro caso, suele producir la reaparición del cuadro diarreico.

Las complicaciones gastrointestinales durante el tratamiento con carbamacepina se han descrito en el 0-9\% de los casos destacando anorexia, náuseas, vómitos, estreñimiento y en raras ocasiones diarrea. En la mayor parte de los casos estas complicaciones son leves y no obligan a suspender el tratamiento (1). Sin embargo, excepcionalmente se ha asociado la carbamacepina a un cuadro de diarrea crónica formando parte de un síndrome de hipersensibilidad (6), asociada a colitis eosinófila (7) o CL (8), como en el caso que presentamos y que nos obligaría a retirar el fármaco.

Con este caso queremos llamar la atención sobre un cuadro poco frecuente, en el que dada la ausencia de hallazgos en los estudios analíticos, radiológicos y endoscópicos conviene tener un alto índice de sospecha para su diagnóstico, debiendo además considerar la posibilidad de que diversos fármacos como la carbamacepina puedan ocasionarlo y que por tanto su suspensión permitirá la resolución del cuadro.

\section{P. Álvarez-Pérez, E. Rubio-Nazábal'1, J. Marey-López ${ }^{1}$, S. López-Facal ${ }^{1}$, P. Rey del Corral ${ }^{1}$}

Medicina Familiar y Comunitaria. Ambulatorio La Torre. ${ }^{\text {SServi- }}$ cio de Neurología. Hospital Juan Canalejo. La Coruña

1. Pellock JM. Carbamacepine side-effects in children and adults. Epilepsia 1987; 28 (Supl. 3): S64-70.

2. Lazenby AJ, Yardley JH, Giardiello FM, et al. Limphocytic ("microscopic") colitis: a comparative histopathologic study with particular reference to colagenous colitis. Hum Pathol 1989; 20: 18-28.

3. Beaugerie L, Luboinski J, Brousse N, et al. Drug induced lymphocytic colitis. Gut 1994; 35: 426-8.

4. Beaugerie L, Patey N, Brosse N. Ranitidine, diarrhoea, and lymphocytic colitis. Gut 1995; 37: 708-11.

5. Martínez Avilés P, Gisbert Moya C, Berbegal Serra J, et al. Colitis linfocitaria inducida por ticlopidina. Med Clin (Barc) 1996; 106: 317.

6. Eland IA, Dofferhoff AS, Vink R, et al. Colitis may be part of the antiepileptic drug hipersensibility syndrome. Epilepsia 1999; 40: 1780-3.

7. Anttila VJ, Valtonen M. Carbamazepine-induced eosinophilic colitis. Epilepsia 1992; 33: 119-21

8. Mahajan L, Wyllie R, Goldblum J. Lymphocytic colitis in a pediatric patient: a possible adverse reaction to carbamazepine. Am J Gastroenterol 1997; 92: 2126-7 